\title{
Prevalence of Burnout among Dental Students during COVID-19 Lockdown in UAE
}

\author{
Natheer H Al-Rawi ${ }^{1}$, Ala' Yacoub², Ala Zaouali ${ }^{3}$, Lina Salloum ${ }^{4}$, Noura Afash ${ }^{5}$, Omar A Shazli ${ }^{6}$, Zeina Elyan ${ }^{7}$
}

\begin{abstract}
Aim: To estimate the prevalence of burnout among dental students in two major universities in the United Arab Emirates during the coronavirus disease-2019 (COVID-19) lockdown.

Materials and methods: In this cross-sectional observational study, the burnout clinical subtype questionnaire (BCSQ-12-SS) (English version) was used. It consists of 12 questions covering domains of overload (4 questions), lack of development (4 questions), and neglect (4 questions). The questionnaire was sent to 500 dental students from the University of Sharjah (UOS) and Ajman University of Science and Technology (AUST). The association between burnout and sociodemographic variables was also investigated.

Results: The majority of responders were females (74\%). Socio-demographic and study characteristics of dental students from both universities were not remarkably different. However, the responses to the BCSQ-12-SS questions were not very different. In this study, there was no significant association between burnout and demographic variables, such as age, gender, relationships, distance from family, residency, year of study, studying hours, and number of failed subjects. However, there was a significant association between burnout and receiving a scholarship and family support.

Conclusion: Identifying individuals at risk for burnout may provide a potential intervention strategy and counseling to assist in dental student development, as it has good psychometric properties.

Clinical significance: Burnout among dental students could develop into anxiety and depressive disorders. Early identification and prevention will protect the psychological well-being of dentists.

Keywords: BCSQ-12-SS, Burnout, Dental students, Lockdown, Psychometrics.

The Journal of Contemporary Dental Practice (2021): 10.5005/jp-journals-10024-3072
\end{abstract}

\section{INTRODUCTION}

A lifestyle filled with constant stresses, anxiety, and pressure is detrimental to many individuals as it can result in what was described by American psychologist Herbert Freudenberg as burnout. Burnout is a state of emotional and physical exhaustion as well as inefficacy. ${ }^{1}$ Burnout is the product of a combination of several dimensions, namely "overload", "lack of development", and "neglect", which unify to degrade one's efficiency. ${ }^{2}$ "Overload" describes feelings of excessive investment of one's effort and health in pursuance of success, "lack of development" explains the lack of personal growth and consequently wanting to pursue other careers to allow improvement, and "neglect" refers to the indifference felt when facing difficulties. This resultant state of exhaustion was observed in varying professions and has also been documented among university students, with a more marked prevalence among students in healthcare majors, such as medicine, nursing, and dentistry. ${ }^{2}$

During the unprecedented era of the coronavirus disease-2019 (COVID-19) pandemic, the majority of countries worldwide have adopted very strong measures. Lockdown has been used to contain the spread of infection.

Universities closed their doors, and education continued online. These preventive measures, despite their effectiveness in the containment of the pandemic spread, also has detrimental effects on the mental health of people like symptoms of depression, anxiety, and stress. ${ }^{3}$
${ }^{1-7}$ Department of Oral and Craniofacial Health Sciences, College of
Dental Medicine, University of Sharjah, Sharjah, United Arab Emirates
Corresponding Author: Natheer H Al-Rawi, Department of Oral and
Craniofacial Health Sciences, College of Dental Medicine, University of
Sharjah, Sharjah, United Arab Emirates, Phone: +971 551100169, Fax:
+97165057606, e-mail: nhabdulla@sharjah.ac.ae

How to cite this article: Al-Rawi NH, Yacoub A, Zaouali A, et al. Prevalence of Burnout among Dental Students during COVID-19 Lockdown in UAE. J Contemp Dent Pract 2021;22(5):538-544.

Source of support: Nil

Conflict of interest: None

Burnout plays a significant role in the overall wellbeing of university students and has severe implications for the continuation of burnout during the lockdown and even beyond.

University students, particularly dental students are very vulnerable to burnout and its consequences, like poor work engagement ${ }^{4}$ and poor wellbeing. ${ }^{5}$

The psychological impact of infectious disease outbreaks on students has been previously studied. One such study reported that almost one-quarter of medical students in Saudi Arabia recorded mild to moderate anxiety levels during Middle East respiratory syndrome (MERS) and severe acute respiratory syndrome (SARS) outbreaks. ${ }^{6}$ Another study in Hong Kong reported that anxiety levels were found to be significantly higher among medical students than non-medical students.

\footnotetext{
() Jaypee Brothers Medical Publishers. 2021 Open Access This article is distributed under the terms of the Creative Commons Attribution 4.0 International License (https://creativecommons.org/licenses/by-nc/4.0/), which permits unrestricted use, distribution, and non-commercial reproduction in any medium, provided you give appropriate credit to the original author(s) and the source, provide a link to the Creative Commons license, and indicate if changes were made. The Creative Commons Public Domain Dedication waiver (http://creativecommons.org/publicdomain/zero/1.0/) applies to the data made available in this article, unless otherwise stated.
} 
Another cross-sectional study was conducted on a sample of 358 undergraduates from 14 universities in Turkey, including 200 female students during the COVID-19 lockdown. They found that students reported high perceived stress, mild generalized anxiety, and low satisfaction with life. ${ }^{8}$

Since the COVID-19 outbreak, very few studies have been conducted to estimate the effect of this pandemic on the psychological health of students, ${ }^{9,10}$ but none has been carried out on dental students in the United Arab Emirates.

In dental education, educational burnout is viewed as concerns about high clinical and educational demands, as well as insecurities about the chosen career path, which results in students developing a negative attitude and a feeling of incompetence. This plays a significant role in decreased interest, learning, and function of individuals. Also, the current lockdown that was brought by the spread of COVID-19adds fuel to the existing stress as the fear and panic associated with the pandemic has been psychologically exhausting. Furthermore, the lockdown has also caused the temporary closure of all educational institutions, forcing students to study from home. Therefore, many clinical requirements necessitating a hands-on approach were left unfinished, which is a major concern for dental students as it affects their educational progress.

Since only a small number of studies have reviewed educational burnout in dentistry, it seemed worthwhile to conduct this research to assess the prevalence of burnout among dental students in the University of Sharjah (UOS) and Ajman University of Science and Technology (AUST) (as two major universities that have dental programs) by having the participants fill out the burnout clinical subtype questionnaire (BCSQ-12-SS) in domains of overload, lack of development, and neglect. The hypothesis is that owing to the constant stressors of dental education alongside the current situation of a pandemic-induced quarantine under which the research was conducted, a high prevalence of educational burnout is expected. Therefore, early identification may allow possibilities for interventional techniques to avert the adverse effects on the physical and mental health of students.

The present study aims to identify the prevalence of burnout among dental students in UOS and AUST during the COVID-19 lockdown period using a standardized BCSQ-12-SS.

\section{Materials and Methods}

This cross-sectional study was approved by the research ethics committee of UOS (REC-20-02-20-01S). The study was analyzed from self-reported data collected from students attending two different dental colleges in the emirates of Sharjah and Ajman in UAE during the first COVID-19 lockdown period (March-April 2020).

\section{Sample Selection}

An English version of online two-part self-administrated questionnaire was distributed among 500 dentistry students from both universities. The chosen sample consisted of dental students from all academic years, that is, from year 1 to year 5 including interns and excluding foundation year students in UOS, or students receiving any psychological management (cognitive or behavioral therapy, or taking any medication, or a combination of both), as well as mentally compromised individuals.

\section{Data Collection}

The online form of the questionnaire consisted of a brief explanation of the purpose of the study and the method of data collection and was filled by consented participants.
The first part of the online questionnaire covers the sociodemographic characteristics of the participants; like the campus (UOS and AUST), age, gender, participant's relationship status, distance from family home, place of residency (with parents, dormitory, shared flat, or private flat), scholarship (yes or no), perceived parental support for one's studies (insufficient, good, or very good), weekly hours spent on studying, number of failed subjects (none, one, two, or more), and years of study (first, second, third, fourth, fifth, or internship). ${ }^{1}$

The second part of the questionnaire consists of twelve questions; Q1-Q4 deals with overload, Q5-Q8 deals with lack of development, and Q9-Q12 deals with neglect. Likert scale was used as 1 = strongly disagree, $2=$ disagree, $3=$ unsure, $4=$ agree, and $5=$ strongly agree.

\section{Statistical Methodology}

To evaluate the result of answers on the Likert scale, weighted means of questions were obtained, and the scale was modified as follows: means of questions were weighed to be consistent with the Likert scale again from $(5-1 / 5)=0.80$, where: $1-1.79=$ strongly disagree, $1.80-2.59=$ disagree, $2.60-3.39=$ unsure, 3.40-4.19= agree), and $4.20-5=5$ (strongly agree). To study the effect of qualitative variables on the response of questions, an independent sample t-test was used for two-level variables, while one way ANOVA test was used for more than two-level variables followed by Tukey's post hoc analysis for pairwise comparisons. In addition, linear regression analysis (backward method) was used to evaluate the effect of significant predictors on burnout scores. Furthermore, Pearson's correlation analysis was done to assess the correlation between scores of questionnaires (overload, lack of development, neglect, and total burnout score). The validity of questionnaire items was evaluated using Cronbach's alpha, considering $0.6-0.8$ or more as a good level of validity. A significant difference was considered at $p<0.05$ using SPSS Version 25 (Chicago, IL, USA).

\section{RESULTS}

Only 385 students out of 500 invitations (response rate is about $77 \%$ ) responded to the study invitation and returned their answers online.

\section{Sociodemographic Characteristics of Dental Students}

Socio-demographic characteristics are presented in Table 1 as count (n) and percent (\%) including university, gender, age, status, relationship, distance from family $(\mathrm{km})$, place of residence, scholarship, family support, weekly studying hours, failed subjects, and the year of study.

\section{Descriptive Statistics of Burnout Questions Used in the Survey}

Descriptive statistics of questions used in the survey are presented in Table 2 as count $(n)$ and percent (\%) for 1-5 Likert scale in addition to weighted mean \pm SD.

Dental students answered the overload questions (Q1-Q4) with an average score of 3.40, which means they agreed with this item. Students answered the questions related to lack of development (Q5Q8) with an average score of 2.90, which means the uncertainty with this item. They also answered the neglect questions (Q9-Q12) with an average score of 2.26, which means they disagreed with this item.

Also, the total burnout score (average of three aforementioned items) was answered with an average score of 2.85 , indicating the uncertainty by most dental students. 
Table 1: Sociodemographic characteristics of dental students $(n=385)$

\begin{tabular}{|c|c|c|c|c|c|c|c|}
\hline Variables & & $n$ & $\%$ & Variables & & $n$ & $\%$ \\
\hline \multirow{3}{*}{ University } & Ajman & 184 & 47.8 & \multirow[b]{2}{*}{ Gender } & Male & 100 & 26.0 \\
\hline & Sharjah & 201 & 52.2 & & Female & 285 & 74.0 \\
\hline & Yes & 156 & 40.5 & \multirow[t]{2}{*}{ Scholarship } & Yes & 141 & 36.6 \\
\hline \multirow[t]{2}{*}{ Relationship } & No & 229 & 59.5 & & No & 244 & 63.4 \\
\hline & $<20$ & 58 & 15.1 & \multirow[t]{3}{*}{ Family support } & Very good & 201 & 52.2 \\
\hline \multirow[t]{2}{*}{ Age (years) } & $20-22$ & 229 & 59.5 & & Good & 158 & 41.0 \\
\hline & $>20$ & 98 & 25.5 & & Insufficient & 26 & 6.8 \\
\hline \multirow[t]{4}{*}{ Status } & Single & 350 & 90.9 & \multirow{4}{*}{$\begin{array}{l}\text { Distance from family } \\
\text { home }(\mathrm{km})\end{array}$} & With family & 224 & 58.2 \\
\hline & Married & 8 & 2.1 & & $<75$ & 29 & 7.5 \\
\hline & Involved & 24 & 6.2 & & $75-150$ & 54 & 14.0 \\
\hline & Other & 3 & 0.8 & & $>150$ & 78 & 20.3 \\
\hline \multirow{3}{*}{$\begin{array}{l}\text { Weekly } \\
\text { studying hours (hrs) }\end{array}$} & $<30$ & 212 & 55.1 & \multirow{3}{*}{ Failed subjects } & None & 331 & 86.0 \\
\hline & $30-40$ & 128 & 33.2 & & One & 41 & 10.6 \\
\hline & $>40$ & 45 & 11.7 & & Two or more & 13 & 3.4 \\
\hline \multirow[t]{6}{*}{ Place of residency } & With parents & 221 & 57.4 & \multirow[t]{6}{*}{ Year of study } & First & 48 & 12.5 \\
\hline & Dorms & 123 & 31.9 & & Second & 51 & 13.2 \\
\hline & Flat & 36 & 9.4 & & Third & 94 & 24.4 \\
\hline & Shared & 5 & 1.3 & & Fourth & 92 & 23.9 \\
\hline & & & & & Fifth & 88 & 22.9 \\
\hline & & & & & Internship & 12 & 3.1 \\
\hline
\end{tabular}

Table 2: Descriptive statistics of questions used in the survey

\begin{tabular}{|c|c|c|c|c|c|c|c|c|}
\hline Questions & & $\begin{array}{l}\text { Strongly } \\
\text { disagree }\end{array}$ & Disagree & Unsure & Agree & $\begin{array}{l}\text { Strongly } \\
\text { agree }\end{array}$ & Mean $\pm S D$ & $\begin{array}{l}\text { Likert scale } \\
\text { Result }\end{array}$ \\
\hline \multirow{2}{*}{$\begin{array}{l}\text { Q1: I think I invest more than is healthy in my } \\
\text { commitment to my studies }\end{array}$} & $n$ & 15 & 62 & 85 & 163 & 60 & & \\
\hline & $\%$ & 3.9 & 16.1 & 22.1 & 42.3 & 15.6 & $3.55 \pm 1.06$ & Agree \\
\hline \multirow{2}{*}{$\begin{array}{l}\text { Q2: I neglect my personal life due to pursuing } \\
\text { great objectives in studying }\end{array}$} & $n$ & 15 & 111 & 37 & 154 & 68 & & \\
\hline & $\%$ & 3.9 & 28.8 & 9.6 & 40 & 17.7 & $3.41 \pm 1.19$ & Agree \\
\hline \multirow{2}{*}{$\begin{array}{l}\text { Q3: I am endangering my health in pursuing } \\
\text { good results in my studies }\end{array}$} & $n$ & 22 & 108 & 65 & 121 & 69 & & \\
\hline & $\%$ & 5.7 & 28.1 & 16.9 & 31.4 & 17.9 & $3.29 \pm 1.21$ & Unsure \\
\hline \multirow{2}{*}{$\begin{array}{l}\text { Q4: I ignore my own needs to satisfy the } \\
\text { requirements of my studies }\end{array}$} & $n$ & 39 & 76 & 67 & 125 & 78 & & \\
\hline & $\%$ & 10.1 & 19.7 & 17.4 & 32.5 & 20.3 & $3.33 \pm 1.28$ & Unsure \\
\hline Overload (average of Q1-Q4) & & & & & & & $3.40 \pm 0.71$ & Agree \\
\hline \multirow{2}{*}{$\begin{array}{l}\text { Q5: I would like to study something else that } \\
\text { would be more challenging to my abilities }\end{array}$} & $n$ & 57 & 139 & 91 & 72 & 26 & & \\
\hline & $\%$ & 14.8 & 36.1 & 23.6 & 18.7 & 6.8 & $2.67 \pm 1.14$ & Unsure \\
\hline \multirow{2}{*}{$\begin{array}{l}\text { Q6: I feel that my current studies are hamper- } \\
\text { ing the development of my abilities }\end{array}$} & $n$ & 47 & 87 & 106 & 101 & 44 & & \\
\hline & $\%$ & 12.2 & 22.6 & 27.5 & 26.2 & 11.4 & $3.02 \pm 1.20$ & Unsure \\
\hline \multirow{2}{*}{$\begin{array}{l}\text { Q7: I would like to study something else in } \\
\text { which I could better develop my talent }\end{array}$} & $n$ & 49 & 115 & 72 & 94 & 55 & & \\
\hline & $\%$ & 12.7 & 29.9 & 18.7 & 24.4 & 14.3 & $2.98 \pm 1.28$ & Unsure \\
\hline \multirow{2}{*}{$\begin{array}{l}\text { Q8: My studies do not provide me with } \\
\text { opportunities to develop my abilities }\end{array}$} & $n$ & 38 & 135 & 68 & 97 & 47 & & \\
\hline & $\%$ & 9.9 & 35.1 & 17.7 & 25.2 & 12.2 & $2.95 \pm 1.22$ & Unsure \\
\hline Lack of development (average of Q5-Q8) & & & & & & & $2.90 \pm 0.95$ & Unsure \\
\hline \multirow{2}{*}{$\begin{array}{l}\text { Q9: When the results of my studies are not } \\
\text { good at all, I stop making an effort }\end{array}$} & $n$ & 94 & 165 & 49 & 47 & 30 & & \\
\hline & $\%$ & 24.4 & 42.9 & 12.7 & 12.2 & 7.8 & $2.36 \pm 1.20$ & Disagree \\
\hline \multirow{2}{*}{$\begin{array}{l}\text { Q10: I give up in response to an obstacle in my } \\
\text { studies }\end{array}$} & $n$ & 120 & 130 & 70 & 47 & 18 & $2.26 \pm 1.16$ & Disagree \\
\hline & $\%$ & 31.2 & 33.8 & 18.2 & 12.2 & 4.7 & & \\
\hline \multirow{2}{*}{$\begin{array}{l}\text { Q11: I give up when faced with any difficulty in } \\
\text { my task as a student }\end{array}$} & $n$ & 138 & 139 & 56 & 37 & 15 & & \\
\hline & $\%$ & 35.8 & 36.1 & 14.5 & 9.6 & 3.9 & $2.10 \pm 1.11$ & Disagree \\
\hline \multirow{2}{*}{$\begin{array}{l}\text { Q12: When the effort invested in studying is } \\
\text { not enough, I give up }\end{array}$} & $n$ & 79 & 182 & 52 & 60 & 12 & & \\
\hline & $\%$ & 20.5 & 47.3 & 13.5 & 15.6 & 3.1 & $2.34 \pm 1.07$ & Disagree \\
\hline Neglect (average of Q9-Q12) & & & & & & & $2.26 \pm 0.77$ & Disagree \\
\hline Total burnout (average of Q1-Q12) & & & & & & & $2.85 \pm 0.58$ & Unsure \\
\hline
\end{tabular}


Table 3: Assessment of validity of questions of the survey using Cronbach's alpha

\begin{tabular}{lll}
\hline Variables & Cronbach's alpha & Validity strength \\
\hline Overload & 0.40 & Moderate \\
Lack of development & 0.79 & Very good \\
Neglect & 0.62 & Good \\
Total burnout & 0.71 & Good \\
\hline
\end{tabular}

The validity of this questionnaire was evaluated using the Cronbach's alpha method as shown in Table 3, which was moderate for overload domain (0.40), very good for lack of development (0.79), and good for neglect domain and total burnout score $(0.62,0.71)$ for students of Sharjah and Ajman, respectively.

\section{Effect of Sociodemographic Factors on Burnout Scores of Dental Students}

The effect of socio-demographic variables on burnout scores is illustrated in Table 4.

All the socio-demographic variables showed no significant effect on burnout scores except for distance from family, scholarship, and studying hours/week $(p<0.05)$.

Regarding distance from family, students who live less than $75 \mathrm{~km}$ away from their families showed a significantly higher level of agreement on overload questions as compared with those who were with their families.

Regarding scholarship, students who received a scholarship showed a significant higher level of disagreement on lack of development questions as compared to those who did not receive any scholarship.

Regarding weekly studying hours, students who were studying 30-40 hours/week, and more than 40 hours/week showed a significantly higher level of agreement on overload questions as compared to those who were studying less than 30 hours.

\section{Predictive Effect of Sociodemographic Factors on Burnout Scores of Dental Students}

Backward regression analysis was applied to evaluate the predictors of burnout scores as illustrated in Table 5.

From the results of regression analysis, it has been seen that weekly studying hours were a significant predictor of overload, while scholarship was a significant predictor of neglect scores. There were no significant predictors regarding lack of development or total burnout.

\section{Correlation Matrix between Different Scores (Overload, Lack of Development, Neglect, Total Burnout)}

There was a significant positive correlation between all burnout scores as shown in Table 6.

The correlation of overload, lack of development, neglect scores was positively strong with total burnout score. The correlation of overload score was positively weak with lack of development, and neglect scores, while lack of development and neglect scores were moderately positively correlated with each other.

\section{Discussion}

In the past few years, the interest in the occurrence and prevalence of educational burnout among dental students has been increasing, with several studies conducted to bring light to the matter. A study carried out in 2011 by Montero-Marin et al. in Spain has adapted a short version of the "burnout clinical subtype questionnaire" to be applied to students in the dental field through the "burnout clinical subtype questionnaire-12-SS" or "BCSQ-12-SS", with results favoring its usage. ${ }^{2}$ Another study was conducted in Iran by Mohebbi et al. to evaluate the psychometric characteristics of the bridged adaptation and has concluded that the survey has construct as well as convergent and divergent. ${ }^{11}$

In the present study, the age of dental students had no significant effect on educational burnout. The fact that students who participated in our study from both universities were all in a close age range might be the reason behind this. The entire study populations were undergraduate students and interns, who are generally young. Similar results were conducted in many studies. In terms of COVID-19 lockdown situations, Hull et al. reported that age has no quarantine-related negative psychological outcomes. ${ }^{12}$ Whereas, Taylor et al. reported that individuals who are younger (14-24-year-old) are more prone to negative psychological effects during quarantine, thus more subject to educational burnout. ${ }^{13}$

Since lockdown was imposed due to COVID-19, online education was taking place in both participating universities at the time of questionnaire distribution. Volchok's study showed that online classes, in comparison to face-to-face classes, had no effect on male students' performance and they had the same chance of getting a passing grade. Whereas, females had a significantly higher possibility of earning a passing grade. ${ }^{14}$ On the other hand, Cava et al. and Brooks et al. reported that females are more prone to negative psychological outcomes during quarantine, 15,16 resulting in higher chances of educational burnout, even though females exhibited higher academic performance than males in general. ${ }^{14}$ Montero-Marin et al. found no significant difference in educational burnout of female and male dental students. ${ }^{2}$ Their finding was in line with our findings, which indicated that females and males have equal performance in fields in which males used to be dominant. The stresses of girls competing with boys no longer exist. ${ }^{17}$

In the present study, educational burnout of students was not significantly correlated to the relationship status. Mohebbi et al. reported the same results. ${ }^{11}$ However, due to family support provided to married students in UAE, students seem to have fewer financial difficulties than single students. Contrarily, married students might have higher responsibilities, interfering with their educational progress. Mafla et al. reported that older students, married students, and students in higher semesters had higher levels of educational burnout among Colombian dental students. ${ }^{18}$ Cava et al. suggested that demographic factors including the marital status have no association with quarantine-related negative psychological impacts but having one child as opposed to no children may be correlated. ${ }^{15,17}$

Higher levels of educational burnout were reported to be in correlation with living independently and away from parents since students who live alone are no longer supported by their families. This makes them exposed to educational burnout. Also, people who live alone can find the experience of being quarantined away from their families is challenging. ${ }^{19}$ However, in our study, the students' residential status and distance from the family had no significant effect on the educational score of the questionnaire. This might be due to the fact that students who live away from their parents were actually with their families at the time of questionnaire distribution, since quarantine regulations including dormitories closure were announced in early March 2020. 


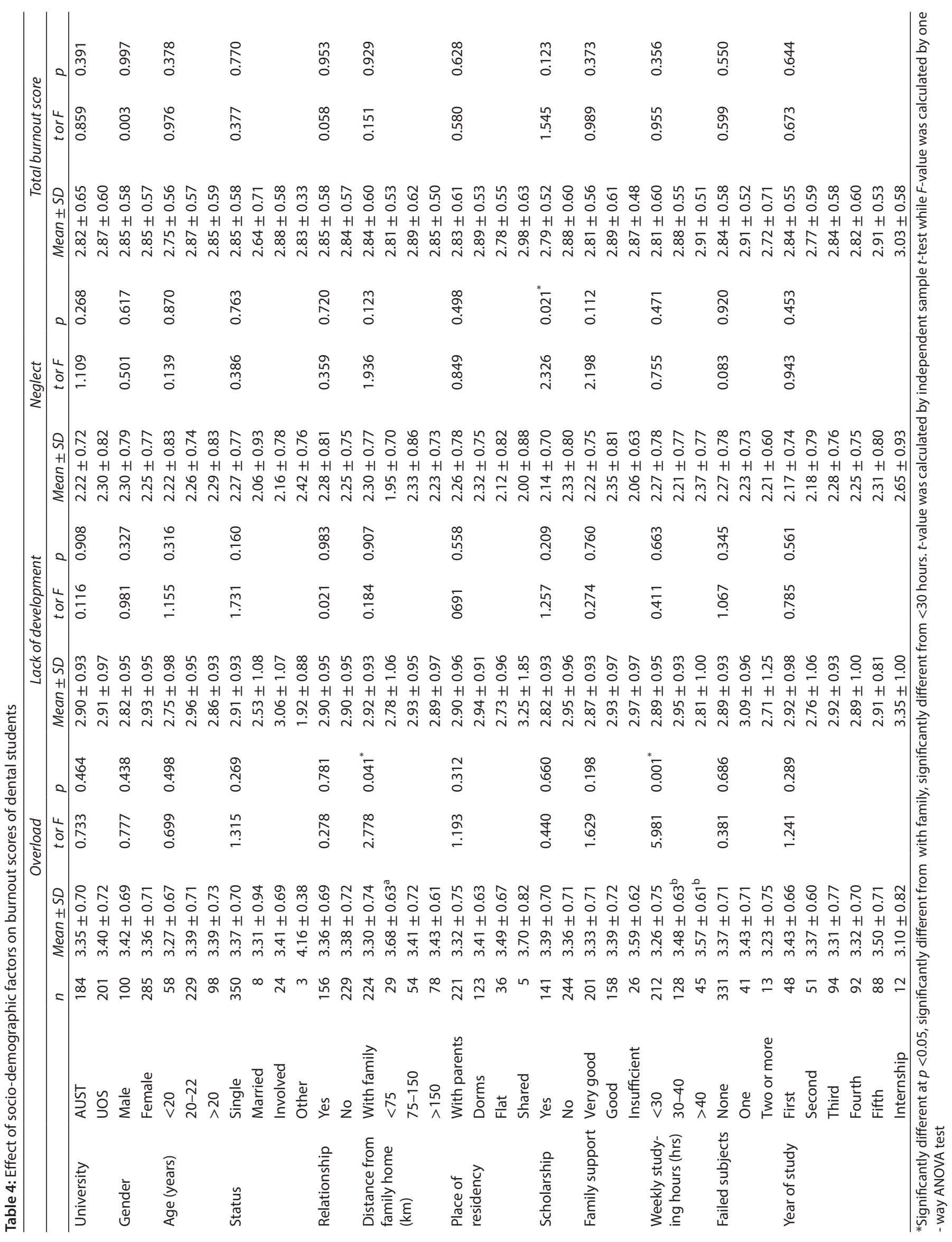


Burnout among Dental Students

Table 5: Backward linear regression analysis to study the predictive effect of socio-demographic factors on burnout scores of dental students

\begin{tabular}{|c|c|c|c|c|c|}
\hline \multirow[t]{2}{*}{ Variable } & & \multicolumn{2}{|c|}{ Unstandardized coefficients } & \multicolumn{2}{|c|}{ Standardized coefficients } \\
\hline & & $B$ & SE & Beta & $p$-value \\
\hline \multirow[t]{3}{*}{ Overload } & Place of residency & 0.088 & 0.050 & 0.089 & 0.078 \\
\hline & Family support & 0.111 & 0.057 & 0.098 & 0.053 \\
\hline & Weekly studying hours & 0.167 & 0.051 & 0.164 & $0.001^{*}$ \\
\hline Lack of development & \multicolumn{5}{|c|}{ Non-significant variable } \\
\hline Neglect & Scholarship & 0.189 & 0.081 & 0.118 & $0.021^{*}$ \\
\hline Total burnout & \multicolumn{5}{|c|}{ Non-significant variable } \\
\hline
\end{tabular}

*Significantly different at $\mathrm{p}<0.05$; B: for beta coefficient; se, standard errors

Table 6: Correlation matrix between different scores (overload, lack of development, neglect, and total burnout)

\begin{tabular}{llcccc}
\hline Score variable & & Overload & Lack of development & Neglect & Total burnout \\
\hline Overload & $r$ & 1 & $0.238^{* *}$ & $0.137^{* *}$ & $0.601^{* *}$ \\
& $p$-value & & $<0.0001$ & 0.007 & $<0.0001$ \\
Lack of development & $r$ & $0.238^{* *}$ & 1 & $0.359^{* *}$ & $0.806^{* *}$ \\
& $p$-value & $<0.0001$ & $<0.0001$ & $<0.0001$ & $0.700^{* *}$ \\
Neglect & $r$ & $0.137^{* *}$ & $0.359^{* *}$ & $<.0001$ \\
& $p$-value & 0.007 & $<0.0001$ & $0.700^{* *}$ & 1 \\
Total burnout & $r$ & $0.601^{* *}$ & $0.806^{* *}$ & $<0.0001$ \\
& $p$-value & $<0.0001$ & $<0.0001$ & & $<0.001$ \\
\hline
\end{tabular}

**Significant correlation at $p<0.01 ; r$, Pearson's correlation coefficient

According to the results of our research, family support significantly affected the risk of developing burnout $(p=0.016)$. Levens et al. concluded in their study that the impact of family emotional support on reducing burnout symptoms depended on the level of stress reactivity. In other words, a higher family emotional support would be more effective only if the stress reactivity was low. Otherwise, the effect of higher family emotional support would not be significant. ${ }^{20}$ This could explain why the majority of the respondents in our study who had good family support showed signs of burnout and were at risk.

According to the results of the present study, there seemed to be a significant correlation between the acquirement of a scholarship and the risk of burnout ( $p=0.019)$. Most of the participants were not granted scholarships and showed high scores for burnout. This could be related to the failure to understand certain learning techniques or disinterest in learning. ${ }^{21}$ It could also be due to the financial toll of their education, as it can create concerns for those who have limited financial support, especially during the lockdown period, when thinking about their ability to finish their education, had they not obtained a scholarship. This was supported by Brooks et al., in which they reported that negative stressors of quarantine included financial loss. ${ }^{16}$ Whereas, adequate financial support can significantly prevent burnout. In contrast, Montero-Marin et al. concluded in their study that students who did obtain a scholarship achieved higher burnout scores. The reason was that students with scholarships can become neglectful given that their academic performance would grant them a scholarship the following year, therefore, they would not need to justify their current scholarship. ${ }^{2}$

As for the weekly hours spent on studying, they did not seem to be associated with the burnout risk in our study. However, the majority of respondents who invested less than 30 hours revealed high scores. It has been proposed that such results may be justified by lack of enthusiasm and loss of interest in studying or feeling stressed and unable to focus on studies, especially if experienced frequently. The fact that the respondents completed the questionnaire during a pandemic-induced lockdown could be a contributing factor. It has been proposed that insistence of social distancing shone a light on online distance learning, which allowed students room to procrastinate, due to the greater flexibility and lack of self-discipline and motivation. Consequently, less than satisfactory grades and grade point average (GPAs) can be the product, which yields directly to high burnout risks. On the other hand, Montero-Marin et al. in their study found that students who spent more hours studying experienced greater levels of exhaustion. Hence, they were more likely to score high and become at burnout risk. ${ }^{2}$

The variable "failed subjects" in our study did not seem to be in association with being at risk of burnout. It is worth mentioning that majority of our samples who did not fail any subject showcased high scores when responding to the questions of the BCSQ-12-SS. In terms of quarantine, a lot of the respondents' lives were disrupted, therefore, stressing about maintaining grades amidst a period of unrest could have taken its toll on them. Also, those who passed all subjects may be high achievers who overload themselves to pursue success on the account of their health; thus, they would experience greater levels of exhaustion. On the contrary, several studies reported that failing courses and having low GPA scores were consistent with higher burnout levels. For example, Shadid et al. reflected that failing subjects in college acts as an additional source of stress since students would need to work harder and pass the course for them to pass the year. ${ }^{22}$ Regarding the academic year of study, the results of our study indicated that the year of study did not significantly impact the risk of having burnout. The greater majority of the respondents from all years showed at least a few signs of burnout. This is in contrast to other studies that demonstrated different responses, with students from second to fourth year being at a greater risk.

For instance, Shadid et al. showed results of higher stress and burnout rates among first- and fourth-year students, with first-year 
undergraduates experiencing additional stress brought by adapting to a new and competitive environment, learning new subjects, as well as perceived lack of time. ${ }^{22}$ Montero-Marin et al. reported that fifth-year seniors were less likely to be overloaded and experience burnout compared to younger years. They reasoned that since they have come this far in their academic careers, they would have already adapted to the stresses and learned to better manage them. ${ }^{2}$ Contrarily, Dyrbye et al. mentioned how seniors, who were close to graduating, expressed growing concerns in regards to having deficient skills and not being able to meet their parent's high expectations, which yielded to higher stress and exhaustion levels as compared to the younger juniors. ${ }^{23}$ The cancellation of graduation as a result of social distancing restrictions could have also played a role, as reported.

This study presented some shortcomings. Regardless of the total number of participants from both universities that provided a sufficient response rate, the generalization of all dental students in the country cannot be made. Another drawback is having a crosssectional design. A longitudinal design would be more preferable for further confirmation of the correlations. Furthermore, our data were obtained from dental students during lockdown situations that might have affected the scores. No previous reports from the same two universities regarding educational burnout were made during regular studying situations. This prevented any comparisons to be made. Thus, the actual effect of quarantine, whether it was positively or negatively affecting the burnout risks of students, will need to be further investigated.

\section{CONCLUSION}

The BCSQ-12-SS questionnaire can be used to determine the level of educational burnout among dental students. It also can classify the level of burnout according to the resultant score independently for each institute/university. Also, socio-demographic variables of the participants were found to have some impact on different subtypes of the questionnaire. Therefore, a specified intervention according to the level of burnout must be employed to help students preserve their mental health, which would in turn result in relief of study barriers.

\section{References}

1. Kulkarni S, Dagli N, Duraiswamy $\mathrm{P}$, et al. Stress and professional burnout among newly graduated dentists. J Int Soc Prev Community Dent 2016;6(6):535-541. DOI: 10.4103/22310762.195509 .

2. Montero-Marin J, Monticelli F, Casas M, et al. Burnout syndrome among dental students: a short version of the "Burnout Clinical Subtype Questionnaire" adapted for students (BCSQ-12-SS). BMC Med Educ 2011;11(1):103. DOI: 10.1186/1472-6920-11-103.

3. Ozamiz-Etxebarria N, Mendragon NI, Santamaria MD, et al. Psychological symptoms during the two stages of lockdown in response to the COVID-19 outbreak: an investigation in a sample of citizens in North Spain. Front Psychol 2020;11:1491. DOI: 10.3389/ fpsyg.2020.01491.

4. Zis P, Anagnostopoulos F, Artemiadis AK. Residency training: work engagement during neurology training. Neurology 2016;87(5):e45e48. DOI: 10.1212/WNL.0000000000002911.
5. Hall LH, Johnson J, Watt I, et al. Healthcare staff wellbeing, burnout, and patient safety: a systematic review. PLoS One 2016;11(7):e0159015. DOI: 10.1371/journal.pone.0159015.

6. Al-Rabiaah A, Temsah MH, Al-Eyadhy AA, et al. Middle East respiratory syndrome-corona virus (MERS-CoV) associated stress among medical students at a university teaching hospital in Saudi Arabia. J Infect Public health 2020;13(5):687-691. DOI: 10.1016/j.jiph.2020.01.005.

7. Wong TW, Gao Y, Tam WWS. Anxiety among university students during SARS epidemic in Hong Kong. Stress Health 2007;23(1):31-35. DOI: 10.1002/smi.1116.

8. Aslan I, Ochnik D, Çınar O. Exploring perceived stress among students in Turkey during the COVID-19 pandemic. Int J Environ Res Public Health 2020;17(23):8961. DOI: 10.3390/ijerph17238961.

9. Cao W, Fang Z, Hou G, et al. The psychological impact of the COVID-19 epidemic on college students in China. Psychiatry Res 2020;287:112934. DOI: 10.1016/j.psychres.2020.112934.

10. Saddik B, Hussein A, Sharif-Askari F, et al. Increased level of anxiety among medical and non-medical university students during the COVID-19 pandemic in the United Arab Emirates. Risk Manag Health Policy 2020;13:2395-2406. DOI: 10.2147/RMHP.S273333.

11. Mohebbi SZ, Yazdani R, Talebi M, et al. Burn out among Iranian dental students: psychometric properties of burnout clinical subtype questionnaire (BCSQ-12-SS) and its correlates. BMC Med Educ 2019;19(1):388. DOI: 10.1186/s12909-019-1808-3.

12. Hull HF, Styra R, Hawryluck L, et al. SARS control and psychological effects of quarantine, Toronto, Canada. Emerg Infect Dis 2005;11(2):354-355. DOI: 10.3201/eid1102.040760.

13. Taylor MR, Agho KE, Stevens GJ, et al. Factors influencing psychological distress during a disease epidemic: data from Australia's first outbreak of equine influenza. BMC Public Health 2008;8(1):347. DOI: 10.1186/1471-2458-8-347.

14. VolchokE. Differences in the performance of male and female students in partially online courses at a community college. Community Coll J Res Pract 2019;43(12):904-920. DOI: 10.1080/10668926.2018.1556134.

15. Cava MA, Fay KE, Beanlands HJ, et al. The experience of quarantine for individuals affected by SARS in Toronto. Public Health Nurs 2005;22(5):398-406. DOI: 10.1111/j.0737-1209.2005.220504.x.

16. Brooks SK, Webster RK, Smith LE, et al. The psychological impact of quarantine and how to reduce it: rapid review of the evidence. Lancet 2020;395(10227):912-920. DOI: 10.1016/S0140-6736(20)30460-8.

17. Singh $P$, Aulak DS, Mangat SS, et al. Systematic review: factors contributing to burnout in dentistry. Occup Med 2016; 66(1):27-31. DOI: $10.1093 /$ occmed/kqv119.

18. Mafla AC, Villa-Torres L, Polychronopoulou A, et al. Burnout prevalence and correlates amongst Colombian dental students: the STRESSCODE study. Eur J Dent Educ 2015;19(4):242-250. DOI: 10.1111/eje.12128.

19. Johal SS. Psychosocial impacts of quarantine during disease outbreaks and interventions that may help to relieve strain. N Z Med J 2009;122(1296):47-52.

20. Levens SM, Elrahal F, Sagui SJ. The role of family support and perceived stress reactivity in predicting depression in college freshman. J Soc Clin Psychol 2016;35(4):342-355. DOI: 10.1521/jscp.2016.35.4.342.

21. Ling L, Qin S, Shen LF. An investigation about learning burnout in medical college students and its influencing factors. Int J Nurs Sci 2014;1(1):117-120. DOI: 10.1016/j.ijnss.2014.02.005.

22. Shadid A, Shadid AM, Shadid A, et al. Stress, burnout, and associated risk factors in medical students. Cureus 2020;12(1):e6633. DOI: 10.7759/cureus.6633.

23. Dyrbye LN, Thomas MR, Shanafelt TD. Systematic review of depression, anxiety, and other indicators of psychological distress among U.S. and Canadian medical students. Acad Med 2006;81(4):354-373. DOI: 10.1097/00001888-200604000-00009. 